\title{
Eosinophilic Esophagitis: Demographic, Clinical, Endoscopic, Histologic, and Atopic Characteristics of Children and Teenagers in a Region in Central Spain
}

\author{
Gómez Torrijos E1', Sánchez Miranda P2, Donado Palencia P², Castro Jimenez A', \\ Rodriguez Sánchez J33, Mendez Díaz Y1', Moreno Lozano L'1, García \\ Rodríguez $\mathrm{R}^{1}$
}

'Allergy Department, Hospital General Universitario de Ciudad Real, Ciudad Real, Spain

${ }^{2}$ Pediatric Department, Hospital General Universitario de Ciudad Real, Ciudad Real, Spain

${ }^{3}$ Digestive Department, Hospital General Universitario de Ciudad Real, Ciudad Real, Spain

J Investig Allergol Clin Immunol 2017; Vol. 27(2): 104-110

doi: 10.18176/jiaci.0112

\section{Abstract}

Background and objective: Eosinophilic esophagitis $(\mathrm{EoE})$ is an increasingly prevalent chronic inflammatory disease of the esophagus with an immunoallergic etiology. Few studies have been published on EoE in children and adolescents. The objective of this study was to analyze the demographic, clinical, serologic, endoscopic-histologic, and atopic characteristics of pediatric patients with EoE and to identify atopic and digestive comorbidities.

Methods: We conducted a prospective observational study in children and adolescents ( $<16$ years) assessed in a specialized multidisciplinary EoE unit in a tertiary referral hospital in a central region of Spain between 2011 and 2015.

Results: Thirty-five patients were included in the study. Twenty-eight (80\%) were male. The mean age was 9.6 years, $83 \%$ were atopic, and $28 \%$ reported a family history of atopy. The most common symptom was dysphagia (51\%). Eosinophilia was detected in the blood of $60 \%$ of patients. Eosinophil cationic protein and total lgE were elevated in $88 \%$ and $77 \%$ of patients, respectively. The most frequent endoscopic finding was linear grooves (57\%). Skin tests with aeroallergens were positive in $82 \%$ of patients (pollen $62 \%$ and food $60 \%$ ). The main atopic comorbidities were asthma (48\%) and rhinoconjunctivitis (37\%). Digestive diseases were more often associated with gastritis and Helicobacter pylori infection (17\%).

Conclusions: Our results are similar to those previously reported. EoE is more common in boys and in individuals with a history of atopy and sensitization to airborne allergens and food. These results support the consideration of EoE as an atopic disease and underline the important role of allergists in early diagnosis and treatment.

Key words: Children. Teenagers. Eosinophilic esophagitis. Atopic comorbidities. Digestive comorbidities. Allergens. Esophagoscopy.

\section{Resumen}

Introducción y objetivos: La esofagitis eosinofílica (EoE) es una enfermedad inflamatoria crónica, emergente del esófago, con etiología inmunoalérgica. Hasta ahora, pocos estudios sobre esta enfermedad en niños y adolescentes han sido publicados. El objetivo de este estudio era estudiar las características epidemiológicas, clínicas, serológicas y endoscópico-histológicas de estos pacientes y las comorbilidades alergológicas y digestivas.

Metodología: Es un estudio observacional descriptivo en niños y adolescentes ( $<16$ años), estudiados en una unidad multidisciplinar en un hospital de tercer nivel en una región del centro de España.

Resultados: Se incluyeron en el estudio 35 pacientes. 28 eran hombres (80\%). La edad media era 9,6 años, el 83\% eran atópicos y tenían antecedentes familiares de atopia el $28 \%$. El síntoma más común fue la disfagia (51\%). Se detectó eosinofilia en sangre en el $60 \%$ de los pacientes. La proteína catiónica del eosinófilo y la lg E total estaban elevadas en el $78 \%$ y $77 \%$ de los pacientes, respectivamente. El hallazgo endoscópico más frecuente fueron los surcos lineales (62\%). Loa tests cutáneos fueron positivos en el $82 \%$ de los pacientes (polen 62\%, alimentos 60\%). Las comorbilidades atópicas fueron, asma (48\%) y rinoconjuntivitis (37\%). Las enfermedades digestivas más asociadas fueron gastritis e infección por Helicobacter pylori (17\%). 
Conclusiones: Nuestros resultados son similares a los publicados previamente. La EoE es mas frecuente en niños, con historia de atopia, sensibilizados a aeroalérgenos o alimentos. Estos resultados apoyan que la EoE pueda considerarse una enfermedad atópica y el importante papel del alergólogo en el diagnóstico y tratamiento precoz de esta enfermedad.

Palabras clave: Niños. Adolescentes. Esofagitis eosinofílica. Comorbilidades atópicas. Comorbilidades digestivas. Alérgenos. Esofagoscopia.

\section{Introduction}

Eosinophilic esophagitis (EoE) has been defined as a chronic immune/antigen-mediated esophageal inflammatory disease characterized clinically by esophageal dysfunction and histologically by eosinophil-predominant inflammation [1]. Its prevalence varies from 0.89 cases per 10000 inhabitants in Western Australia to 4 cases per 10000 infants in Ohio, United States. In Europe, an annual incidence of 0.16 cases per 10000 population has been reported in southern Denmark [2]. According to recent reports, the incidence and prevalence of EoE has increased notably throughout the world [3].

Studies conducted in children suggest that the symptoms of EoE are triggered by food allergens in many cases [1]. A recent report described the development of EoE in 3 adults after exposure to aeroallergens [4]. Whether this also occurs in pediatric patients remains to be demonstrated, although seasonal exacerbation of the disease has been reported in children [5].

The lack of an early diagnosis and treatment during childhood or adolescence may result in sequelae or complications, even in proton pump inhibitor-responsive esophageal eosinophilia (PPI-REE) [6].

Because of its similarities to other allergic diseases, EoE has been considered to be an allergic condition, or more specifically, a form of food allergy because patients tend to have food sensitization and experience an improvement in symptoms and inflammation after the elimination of certain foods [7]. The optimal means of identifying causative foods remains unclear. A food is considered to cause EoE if its elimination from the patient's diet leads to resolution of esophageal eosinophilia and its reintroduction leads to recurrence of EoE [8].

The objectives of this study were to describe the demographic, clinical, endoscopic, histologic, and atopic characteristic of pediatric patients with EoE in the city and province of Ciudad Real in central Spain; evaluate relevant laboratory parameters such as total IgE, serum eosinophil cationic protein (ECP), and peripheral blood eosinophil count; calculate the frequency of allergic sensitization to foods and aeroallergens; determine the prevalence of EoE in patients with a history of oral immunotherapy with foods (milk and egg); and identify atopic and digestive comorbidities.

\section{Methods}

\section{Patient Selection and Eligibility}

This was a prospective observational study including children and teenagers $(<16$ years of age) consecutively assessed in a specialized multidisciplinary EoE unit in a tertiary referral university hospital in Ciudad Real. The unit is composed of the following services: pediatric gastroenterology (children aged 0-13 years), adult gastroenterology (teenagers aged 13-16 years), and allergology (children and teenagers aged 0-16 years). Patients diagnosed with EoE from January 2011 to December 2015 by any of the 3 services were included.

The diagnostic criteria for EoE included: $a$ ) upper gastrointestinal symptoms (nausea and vomiting, abdominal and chest pain, lump in throat or chest, deglutition disorder, halitosis) dehydration, chronic cough, and symptoms of esophageal dysfunction (dysphagia, choking, etc.); $b$ ) infiltration of esophageal epithelium by $\geq 15$ eosinophilic leukocytes (eos) per high power field (HPF) at 400x light microscopy; and c) exclusion by clinical history of drug intake, parasites, caustics, hematological neoplasms, or other illnesses that could give rise to EoE. Biopsies were taken from the upper and lower thirds of the esophagus, with a minimum of 5 specimens taken from each location. The specimens were routinely processed for histopathologic analysis. All endoscopic exams were carried out by an endoscopist trained in EoE.

The inclusion criteria for the study were a definitive diagnosis of EoE and written informed consent from the children's parents or legal representatives. In the patients diagnosed in $2011(n=6)$, gastroesophageal reflux disease was ruled out by prescribing treatment with omeprazole $(1 \mathrm{mg} / \mathrm{kg} / \mathrm{d}$ for 2 months) prior to the endoscopy. In the remaining patients $(n=34)$, omeprazole was prescribed only after the first endoscopy, and the dose was doubled to rule out PPI-REE [1].

The study was approved by the hospital's ethics and clinical research committee and conducted in accordance with the principles of the World Medical Association and the Declaration of Helsinki.

\section{Demographic Assessment}

The following data were recorded for each patient: age, sex, family and personal history of atopy, exacerbation of symptoms of EoE in the pollen season, and place of residence (rural or urban).

\section{Clinical Assessment and Comorbidities (Allergic and Digestive Disorders)}

Symptoms of esophageal dysfunction [9] and other common digestive symptoms in children with EoE were recorded (Table 1) together with clinical symptoms related to the ingestion of the most frequent foods involved in EoE.

Information on allergies (rhinoconjunctivitis, asthma, atopic dermatitis, anaphylaxis, food allergy, aeroallergen 
allergy) and digestive diseases (gastroesophageal reflux disease, stomach inflammation, Helicobacter pylori, celiac disease, Crohn disease) was also obtained from the patients' medical records.

\section{Serologic Markers}

Peripheral blood eosinophil count, ECP levels, and IgE levels were determined [10] together with specific IgE to a series of foods (cereals, legumes, milk, egg, fish, crustaceans, and nuts) and aeroallergens (mites, pollens, epithelia, and fungi) by ImmunoCAP (Phadia). Concentrations of over $0.35 \mathrm{kU} / \mathrm{L}$ for specific IgE and over $15 \mu \mathrm{g} / \mathrm{mL}$ for serum ECP were considered to be positive.

\section{Endoscopic and Histological Assessment}

All endoscopic procedures were performed under conscious sedation with propofol supervised by an anesthetist. The explorations were performed with a flexible HD gastroscope with an outer diameter of $9 \mathrm{~mm}$ and a working channel of $2.8 \mathrm{~mm}$ (GIF-H180, Olympus Medical Systems) and an Exera II image processor (Olympus Medical Systems). Biopsy specimens were taken with a conventional needle clamp (Radial Jaw 4, Boston Scientific) from the proximal and distal third of the esophagus; at least 5 samples were taken from each section. Samples were fixed with $4 \%$ formaldehyde and sent for histologic analysis. Endoscopic signs suggestive of esophageal dysfunction, such as longitudinal grooves, pseudo rings, and microabscess in the mucosa, were recorded.

The biopsy specimens were sent to the pathology laboratory, where they were embedded in paraffin; serial sections of 3 to $5 \mu \mathrm{m}$ were subsequently prepared and stained with hematoxylin and eosin. The samples were examined under a Nikon Eclipse 80i optical microscope with an HPF (x400) of $0.24 \mathrm{~mm}^{2}$. Samples were also stained with periodic acidSchiff to exclude the presence of fungi. A sample was diagnosed as histologically compatible with EoE when 15 eos/HPF or more were detected, with or without microabscesses. The presence of hyperplasia of the basal layer and the number of eos/HPF sections in the upper, middle, and lower sections were also analyzed.

\section{Allergy Workup}

The allergy study consisted of a standard series of tests [11] to ensure homogeneity and avoid bias. Skin prick tests (SPTs) were performed with a commercial series of aeroallergens (Dactylis glomerata, Lolium perenne, Olea europaea, Cupressus arizonica, Platanus acerifolia, Artemisia vulgaris, Chenopodium alba, Plantago lanceolata, Salsola kali, Cladosporium, Alternaria, Aspergillus, Dermatophagoides pteronyssinus, Dermatophagoides farinae, Lepidoglyphus destructor, and cat and dog dander); food (peanut, corn, wheat, soy, egg white, cod, tuna, prawns, cow's milk, lentils) [11]; and panallergens (lipid transfer protein, profilins, and tropomyosin). These tests were carried out following the recommendations of the European Academy of Allergy and Clinical Immunology. The allergens were supplied by ALK-Abelló Laboratories (Madrid, Spain). Histamine $(10 \mathrm{mg} / \mathrm{mL})$ and normal saline were used as positive and negative controls. A wheal with an
Table 1. Demographic, Serologic, Clinical, and Endoscopic Characteristics of 35 Children and Adolescents with EoE

\begin{tabular}{|c|c|}
\hline \multicolumn{2}{|l|}{ Demographics } \\
\hline Sex M/F (\% M) & $28 / 7(80)$ \\
\hline Age, mean (range), y & $9.6(4-16)$ \\
\hline Rural (vs urban) residence & $10(28.5)$ \\
\hline Personal history of atopy, No. (\%) & $9(26)$ \\
\hline Family history of atopy, No. (\%) & $10(28.5)$ \\
\hline Atopy, No. $(\%)$ & $29(83)$ \\
\hline Milk oral immunotherapy, No. & $3(8.5)$ \\
\hline Egg oral immunotherapy, No. & $3(8.5)$ \\
\hline \multicolumn{2}{|l|}{ Serologic markers } \\
\hline $\begin{array}{l}\text { Serum eosinophil count, mean (range) } \\
\text { cells } / \mathrm{cm}^{3}\end{array}$ & $\begin{array}{l}519(100-1700) \\
\text { (high in } 60 \%)\end{array}$ \\
\hline ECP, mean (range), $\mathrm{mcg} / \mathrm{L}$ & $\begin{array}{c}36(8-171) \\
\text { (high in } 88 \%)\end{array}$ \\
\hline Total IgE, mean (range), kU/L & $\begin{array}{c}508(11-10550) \\
\text { (high in } 77 \%)\end{array}$ \\
\hline Positive genetic test for celiac disease, No. (\%) & $1(3)$ \\
\hline Seasonal reactivation of EoE, No. (\%) & $0(0)$ \\
\hline \multicolumn{2}{|l|}{ Clinical findings, No. (\%) } \\
\hline Dysphagia & $18(51)$ \\
\hline Food impaction & $7(20)$ \\
\hline Choking & $2(6)$ \\
\hline Regurgitation & $3(8.5)$ \\
\hline Heartburn & $2(6)$ \\
\hline Abdominal pain & $11(31)$ \\
\hline Chest pain & $3(8.5)$ \\
\hline Lump in the throat & $2(6)$ \\
\hline Nausea and vomiting & $7(20)$ \\
\hline Lump in the chest & $1(3)$ \\
\hline Halitosis & $2(6)$ \\
\hline Deglutition disorder & $5(14)$ \\
\hline Dehydration & $1(3)$ \\
\hline Stunted growth & $2(6)$ \\
\hline Chronic cough & $2(6)$ \\
\hline \multicolumn{2}{|l|}{ Endoscopic and histologic findings } \\
\hline Normal macroscopic endoscopy, No. (\%) & $8(23)$ \\
\hline Phenotypes (inflammatory/fibrostenosis), No. & $27 / 0$ \\
\hline Edema, No. (\%) & $9(26)$ \\
\hline Acanthosis, No. (\%) & $3(8.5)$ \\
\hline Furrows, No. (\%) & $20(57)$ \\
\hline Rings, No. (\%) & $2(6)$ \\
\hline Exudates, No. (\%) & $10(28.5)$ \\
\hline Alterations in the mucus, No. (\%) & $5(14)$ \\
\hline Intestinal villous atrophy, No. (\%) & $3(8.5)$ \\
\hline Eos/hpf upper tract, mean (range), No. & $37(0-100)$ \\
\hline Eos/hpf medium tract, mean (range), No. & $16(0-70)$ \\
\hline Eos/hpf lower tract, mean (range), No. & $47(0-100)$ \\
\hline Basal hyperplasia, No. (\%) & $12(35)$ \\
\hline Degranulation of eosinophils, No. (\%) & $3(8.5)$ \\
\hline
\end{tabular}

Abbreviations: ECP, eosinophilic cationic protein; EoE, eosinophilic esophagitis; Eos/hpf, eosinophils per high-power field. 
area $7 \mathrm{~mm}^{2}$ larger than or a diameter $3 \mathrm{~mm}$ longer than the negative control (saline solution) was considered positive.

We also measured serum total $\mathrm{IgE}$ and specific $\operatorname{IgE}(\mathrm{kU} / \mathrm{L})$ to foods that have been linked to EoE in our setting (milk, egg, wheat, lentils, peanuts, shrimp, and hake).

\section{Statistical Analysis}

Absolute frequencies were calculated for qualitative variables and means, $\mathrm{SD}, 95 \%$ confidence intervals, and ranges were calculated for quantitative variables.

\section{Results}

Thirty-five patients (28 males and 7 females; mean age, 9 years and 6 months; range, 4-16 years) were diagnosed with EoE between 2011 and 2015 at the multidisciplinary EoE unit at our hospital. The demographic, clinical, laboratory, histologic/ endoscopic characteristics are summarized in Table 1 together with details of atopic and digestive comorbidities.

It is important to note that although $83 \%$ of the patients were atopic, no seasonal variations in EoE symptoms were observed; dysphagia was present in more than half of the patients and abdominal pain in nearly one-third. The most common endoscopic finding was linear grooves, followed by exudates. The macroscopic appearance of the endoscopy was normal in $20 \%$ of patients. Eosinophils were more abundant in the distal portion of the esophagus (Table 1). Over $80 \%$ of patients were sensitized to airborne allergens (SPT) and $60 \%$ were sensitized to food. The atopic comorbidities present in more than half of the patients were bronchial asthma, food allergies, and rhinoconjunctivitis. Digestive comorbidities were less prevalent $(<12 \%$ of patients had Helicobacter pylori infection and stomach inflammation (Table 2).

Of the 18 patients with EoE and food allergy, 6 had been treated with oral immunotherapy. Milk was confirmed as the causative agent in the 3 patients treated with oral immunotherapy for cow's milk allergy. The other 3 patients had undergone oral immunotherapy for egg allergy, but a causal link was not established with egg as 2 of the patients did not respond to an egg-free diet and the third refused to continue the study

\section{Discussion}

The demographic characteristics of the series of children and adolescents with EoE described in this study match those reported by other authors $[9,12]$. EoE is more common in white males and in our series it was much more common in those who lived in an urban rather than a rural area. We did not find information on this sociodemographic variable in relation to EoE in the literature, but EoE has been reported to be more prevalent in developed countries [13]. Both the mean age at diagnosis (9.6 years) in our area (central Spain) and the proportion of atopic children and adolescents are similar to those reported by researchers in Texas, United States. A family history of atopy, however, was more uncommon in our series. The authors of the Texan study suggested that early
Table 2. Allergy Study and Comorbidities ${ }^{\mathrm{a}}$

\begin{tabular}{lcl}
$\begin{array}{l}\text { Positive SPT to aeroallergens } \\
28 / 35(82 \%)\end{array}$ & $\begin{array}{l}\text { Positive sIgE } \\
\text { to aeroallergens }\end{array}$ \\
\hline Mites & $3(8.5)$ & $2(6)$ \\
Pollens & $22(63)$ & $4(11.5)$ \\
Fungi & $6(17)$ & $3(8.5)$ \\
Epithelia & $9(26)$ & $4(11.5)$ \\
\hline Positive SPT to foods & $21(60)$ & Positive sIgE to foods \\
Milk & $7(20)$ & $15(43)$ \\
Egg & $8(23)$ & $11(31.5)$ \\
Wheat & $2(6)$ & $9(26)$ \\
Lentils & $6(17)$ & $14(40)$ \\
Prawn & $2(6)$ & $4(11.5)$ \\
Hake & $2(6)$ & $5(14)$ \\
Peanut & $6(17)$ & $13(37)$
\end{tabular}

Positive SPT to panallergens

$\begin{array}{lc}\text { Lipid transfer protein } & 5(14) \\ \text { Profilin } & 4(11.5) \\ \text { Tropomyosin } & 2(6)\end{array}$

\begin{tabular}{lcl}
\hline Atopic comorbidities & & Digestive comorbidities \\
\hline Asthma & $24(68.5)$ & Gastritis 4 (11.5) \\
Rhinoconjunctivitis & $18(51)$ & $\begin{array}{l}\text { Helicobacter pylori 4 } \\
(11.5)\end{array}$ \\
Atopic dermatitis & $4(11.5)$ & Celiac disease 1 (3) \\
Urticaria/angioedema & $2(6)$ & GERD 1 (3) \\
Anaphylaxis & $7(20)$ & Crohn disease 0 (0) \\
Food Allergy & $18(51)$ & \\
Aeroallergen allergy & $20(57)$ &
\end{tabular}

Abbreviations: GERD: gastroesophgeal reflux disease; slgE, specific IgE; SPT, skin prick test.

aData expressed as number (\%) of patients.

onset of allergy in parents may be a predisposing factor for EoE in offspring.

Clinical manifestations of EoE vary with age. Infants and young children typically have nonspecific symptoms, such as vomiting, unexplained feeding difficulties $[14,15]$, abdominal pain, and swallowing disorders [16]. In adolescents, dysphagia and food impaction are predominant $[12,13]$. In exceptional cases, chronic and recurrent cough can be a symptom of EoE in children [17]. EoE should be ruled out in children with stunted growth [18]. The most common symptom in our series was dysphagia, probably because the mean age at diagnosis of EoE was between 9 and 10 years. As in other studies, our patients did not manifest symptoms elicited by the foods most frequently involved in EoE. 
As in adults, analytical parameters such as peripheral blood eosinophilia and elevated total $\operatorname{IgE}$ indicate the presence of atopy in children. ECP is a marker of eosinophilic inflammation, which can be located in any of the organs (esophagus, bronchi, etc). None of the above parameters are useful, however, for the diagnosis of EoE $[1,10]$. Endoscopy with esophageal biopsies is necessary to confirm EoE in children, adolescents, and adults [1].

The macroscopic appearance of the esophageal mucosa may be normal in one-third of patients [19], making it mandatory to take esophageal biopsies by sections. In our series, the endoscopic findings were normal in $23 \%$ of patients. The combination of endoscopy and biopsy findings helped to define the 2 phenotypes of EoE (inflammatory and fibrostenotic) [20]. Stenosis was rare in our series, probably because of the young age of our patients, as stenosis becomes more common as the disease develops [12].

Elimination diets are considered the first-line therapy for EoE in children [21], although they appear to be less effective in adult patients $[22,23]$. That said, in recent years, EoE remission rates of over $70 \%$ have been reported for adults treated with an empiric 6-food elimination diet [24] and diets based on allergy tests [25]. The allergic mechanism of EoE involves both $\operatorname{IgE}$ and non-IgE processes [26], possibly explaining why treatment with diets based on immediate hypersensitivity test results fails in approximately $30 \%$ of cases.

A higher prevalence of sensitization to food extracts has been detected by ImmunoCAP than by skin prick testing in both adults and children [9,27]. A similar situation was observed in our series (Table 1).

Studies of EoE epidemiology and pathophysiology support the link between EoE and allergy in general, while studies of food allergy testing and elimination diets support a link between EoE and food allergy. Although food elimination diets can resolve symptoms in children with EoE, the results of allergy tests and elimination diet studies are not as clear in adults. In addition, aeroallergen sensitizations may play a larger pathophysiological role in adult EoE. Although the consideration of EoE as a form of food allergy is supported by several studies in children and adults, the usefulness of SPT and atopy patch testing for food allergies is still uncertain, and an optimal elimination diet for disease management has yet to be found [28].

The higher prevalence of EoE in patients with atopic diseases suggests a common background with allergy, but neither its etiology nor pathophysiology is clearly understood [21].

EoE shares features with other atopic diseases in terms of pathogenesis, genetics, epidemiology, and treatment options. EoE patients have a higher rate of atopic disease (asthma, allergic rhinitis, atopic dermatitis and food allergy) than the general population $[15,29]$. The patients in our series had a higher proportion of asthma than in other series of EoE patients and the general population. Elevated serum IgE levels have also been associated with a greater risk of bronchial hyperreactivity in individuals with EoE [30]. In our series, bronchial asthma was the most common comorbid allergic disease, coinciding with results from an Asian study [31].

Coexistence of EoE should be suspected in all children who undergo upper gastrointestinal endoscopy for suspected celiac disease, as higher rates of EoE have been reported in children with celiac disease than in the general population (prevalence of $10.7 \%$ in a recent cohort) [32]. Other authors are of the opinion that patients with celiac disease are no more likely to have EoE than patients in whom endoscopy was performed for other reasons [33]. None of the patients in our series had Crohn disease.

EoE reactivations have been reported in the pollen season [5]. In our study we asked about worsening of gastrointestinal symptoms in the pollen season. There was, however, just 1 case of histologically confirmed EoE symptoms in spring and the patient did not experience remission at the end of the season.

Around $2.7 \%$ of children treated with oral immunotherapy with food subsequently develop EoE [34,35]. Our results show a higher rate, as 3 of the 62 patients treated with oral immunotherapy for milk allergy (4.8\%) developed EoE. The patients had complained of dysphagia and a diagnosis of EoE was confirmed after endoscopy with esophageal biopsies; the condition resolved in 3 patients on removing milk from their diet [36]. Three patients on oral immunotherapy with egg also began with dysphagia, but another patient who had discontinued oral immunotherapy with egg 2 years earlier also developed EoE. Therefore, milk may be considered the cause of EoE in the patients who underwent oral immunotherapy for milk allergy. However, the food to which a patient is desensitized may not always be responsible for the EoE, as was the case with egg in our series. In these cases, EoE may be a comorbidity.

Cough was the predominant symptom in 2 children in our series, highlighting the importance of remembering that young children may exhibit a range of symptoms other than the typical gastrointestinal symptoms associated with EoE [37].

Effective treatment of EoE requires a multidisciplinary approach involving gastroenterologists, pediatricians, pathologists, allergists, and sometimes nutritionists and otorhinolaryngologists [16,38]. This multidisciplinary approach is important to prevent both short- and long-term complications of this chronic disease and treatment-related adverse effects [39].

Recent studies support the role of the allergist in the management of EoE, especially for food allergen testing and interpretation and the management of food allergies and concurrent atopic diatheses. In addition, allergists have made significant research contributions to our understanding of EoE [40].

EoE is currently considered to be a chronic health condition whose increasing prevalence is placing a significant burden on the health care system [41].

In conclusion, it is important to rule out EoE both in children with characteristic gastrointestinal symptoms of this disease and in children with atypical manifestations such as chronic cough, stunted growth, or swallowing difficulties. This is particularly important in the case of atopic boys. An upper gastrointestinal endoscopy with biopsies should be performed to ensure an early diagnosis and prevent complications. Allergists play a critical role as they are experts in the treatment of atopic diseases, including avoidance strategies that can improve the quality of life of pediatric patients and their families. 


\section{Acknowledgments}

We thank all the nursing staff at the allergy department of our hospital.

\section{Funding}

The authors declare that no funding was received for the present study.

\section{Conflicts of Interest}

The authors declare that they have no conflicts of interest.

\section{References}

1. Liacouras CA, Furuta GT, Hirano Atkins D, Attwood SE, Bonis PA, Burks AW, Chehade M, Collins MH, Dellon ES, Dohil R, Falk GW, Gonsalves N, Gupta SK, Katzka DA, Lucendo AJ, Markowitz JE, Noel RJ, Odze RD, Putnam PE, Richter JE, Romero Y, Ruchelli E, Sampson HA, Schoepfer A, Shaheen NJ, Sicherer SH, Spechler S, Spergel JM, Straumann A, Wershil BK, Rothenberg ME, Aceves SS. Eosinophilic esophagitis: updated consensus recommendations for children and adults. J Allergy Clin Immunol. 2011;128:3-20.

2. Trivedy P, Teitelbaum JE. Eosinophilic Esophagitis in Children. Paediatr Drugs. 2015; 17(3):227-37.

3. Schroeder S, Capocelli KE, Masterson JC, Harris R, Protheroe C, Lee JJ, Furuta GT. Effect of proton pump inhibitor on oesophageal eosinophilia. J Pediatr Gastroenterol Nutr. 2013; 56:166-72.

4. WolfWA, Jerath MR, Dellon ES. De-novo onset of eosinophilic esophagitis after large volume allergen exposures. J Gastrointestin Liver Dis. 2013; 22:205-8

5. Wang FY, Gupta SK, Fitzgerald JF. Is there a seasonal variation in the incidence or intensity of allergic eosinophilic esophagitis in newly diagnosed children? J Clin Gastroenterol- 2007; 41:451-3.

6. Rassbach W, Rubenstein JH, Elkins M, DeMatos V, Greenson JK, Greenhawt M. Age-based differences in the diagnosis and management of oesophageal eosinophilia. J Allergy Clin Immunol Pract. 2015;3:81-87.

7. Lin SK, Sabharwal G, Ghaffari G. A review of the evidence link in eosinophilic esophagitis and food allergy. Allergy Asthma Proc. 2015; 36:26-33.

8. Spergel JM, Brown-Whitehorn TF, Cianferoni A, Shiker M, Wang ML, Verma R, Liacouras CA. Identification of causative foods in children with eosinophilic esophagitis treated with an elimination diet. J Allergy Clin Immunol. 2012; 130:461-7.

9. Castro Jiménez A, Gómez Torrijos E, García Rodríguez R, Feo Brito F, Borja Segade J, Galindo Bonilla PA, Rodríguez-Sánchez J, Guerra Pasadas F. Demographic, clinical and allergological characteristics of Eosinophilic Esophagitis in a Spanish central region. Allergol Immunopathol. 2014; 42:407-14.

10. Rodríguez-Sánchez J, Gómez-Torrijos E, de-la-Santa-Belda E, López-Viedma B, Martín-Dávila F, Pilkington-Woll JP, Donado-Palencia P, Sánchez-Miranda P, Olmedo-Camacho J. Effectiveness of serological markers of eosinophil activity in monitoring eosinophilic esophagitis. Rev Esp Enferm Dig. 2013:105:462-7.
11. Spergel JM, Beausoleil JL, Mascarenhas M, Liacouras CA. Theuse of skin prick tests and patch tests to identify causative foods in eosinophilic esophagitis. J Allergy Clin Immunol. 2002:109:363-8.

12. Mienlke S. Clinical features of Eosinophilic esophagitis in children and adults. Best Pract Res Clin Gastroenterol. 2015:29:739-48.

13. Dellon ES. Epidemiology of eosinophilic esophagitis. Gastroenterol. Clin North Am. 2014; 43:201-18.

14. Teoh T, Chan ES, Avinashi V, Ko HH, Goldman RD. Diagnosis and management of eosinophilic esophagitis in children. Can Fam Physician. 2015;61:687-90.

15. Cianferoni A, Spergel JM, Muir A. Recent advances in the pathological understanding of eosinophilic esophagitis. Expert Rev Gastroenterol Hepatol. 2015;9:1501-10.

16. Górriz-Gil C, Villarreal IM, Álvarez-Montero Ó, RodríguezValiente A, Magaz M, García-Berrocal JR. Eosinophilic esophagitis: A relevant entity for the otolaryngologist. Acta Otorrinolaringol Esp. 2016; 67(3):167-78

17. Greifer M, Santiago MT, Tsirilakis $K$, Cheng JC, Smith LP. Pediatric patients with chronic cough and recurrent croup: the case of a multidisciplinary approach. Int J Pediatr Otorhinolaryngol. 2015;79:749-52.

18. Paquet B, Bégin P, Paradis L, Drouin E, Des Roches A. High rate of failure to thrive in a paediatric cohort with eosinophilic esophagitis. Ann Allergy Asthma Immunol. 2016; 116: 73-4.

19. Liacouras CA, Spergel JM, Ruchelli E, Verma R, Mascarenhas M, Semeao E, Flick J, Kelly J, Brown-Whitehorn T, Mamula P, Markowitz JE. Eosinophilic esophagitis: a 10-year experience in 381 children. Clin Gastroenterol Hepatol. 2005; 3:1198206.

20. Richter JE. Current Management of Eosinophilic Esophagitis. 2015. J Clin Gastroenterol. 2016; 50(2):99-110.

21. D'Alessandro A, Esposito D, Pesce M, Cuomo R, De Palma GD, Sarnelli G. Eosinophilic esophagitis: From pathophysiology to treatment. World J Gastrointes Pathophysiol. 2015; 6:150-8.

22. Molina-Infante J, Martin-Noguerol $E$, Alvarado-Arenas $M$, Porcel-Carreño SL, Jimenez-Timon S, Hernandez-ArbeizaFJ. Selective elimination diet based on skin testing has suboptimal efficacy for adult eosinophilic esophagitis. J Allergy Clin Immunol. 2012; 130:1200-2.

23. Molina-Infante J, Arias A, Barrio J, Rodríguez-Sánchez J, Sanchez-Cazalilla M, Lucendo AJ. Four-food group elimination diet for adult eosinophilic esophagitis: A prospective multicenter study. J Allergy ClinImmunol. 2014; 134:1093-9.

24. Lucendo AJ, Arias A, Gonzalez-Cervera J,Yagüe-Compadre $J$ L, Guagnozzi D, Angueira T, Jimenez-Contreras S, GonzalezCastillo S Rodriguez-Dominguez B De Rezende LC, Tenias $J M$. Empiric 6-food elimination diet induced and maintained prolonged remission in patients with adult eosinophilic esophagitis: a prospective study on the food cause of the disease. J Allergy Clin Immunol. 2013;131:797-804.

25. Rodríguez-Sánchez J, Gómez Torrijos E, López Viedma B, de la Santa Belda E, Martín Dávila F, García Rodríguez C, FeoBrito F, Olmedo Camacho J, Reales Figueroa P, Molina-Infante J. Efficacy of IgE-targeted vs empiric six-food elimination diets for adult eosinophilic oesophagitis. Allergy. 2014; 69:936-42.

26. Leung J, Beukema KR, Shen AH. Allergic mechanisms of Eosinophilic oesophagitis. Best Pract Res Clin Gastroenterol. 2015: 29:709-20. 
27. Erwin EA, Tripathi A, Ogbogu PU, Commins SP, Slack MA, Cho CB, Hamilton RG, Workman LJ, Platts-Mills TA. IgE Antibody Detection and Component Analysis in Patients with Eosinophilic Esophagitis. J Allergy Clin Immunol Pract. 2015; 3:896-904.

28. Lin SK, Sabharwal G, Ghaffari G. A review of the evidence linking eosinophilic esophagitis and food allergy. Allergy Asthma Proc. 2015; 36:26-33.

29. Spergel JM. An allergist's perspective to the evaluation of Eosinophilic Esophagitis. Best Pract Res Clin Gastroenterol. 2015; 29:771-81.

30. Sehra S, Slaven JE, Kaplan MH, Gupta S, Tepper RS. Increased prevalence of airway reactivity in children with esophagitis. Pediatr Pulmonol. 2016; 51(5):478-83.

31. Kinoshita $Y$, Ishimura N, Oshima N, Ishihara S. Systematic review: Eosinophilic esophagitis in Asian countries. World J Gastroenterol. 2015; 21: 8433-40.

32. Dharmaraj R, Hagglund K, Lyons H. Eosinophilic esophagitis associated with celiac disease in children. BMC Res Notes. 2015; 26:263.

33. Ahmed OI, Qasem SA, Abdulsattar JA, Snow AN, Hill ID. Esophageal eosinophilia in paediatric patients with celiac disease: is it a causal or an incidental association? J Pediatr Gastroenterol Nutr. 2015; 60:493-7.

34. LucendoAJ, Arias A, Tenias JM. Relation between eosinophilic esophagitis and oral immunotherapy for food allergy: a systematic review with meta-analysis. Ann Allergy Asthma Immunol. $2014 ; 113: 624-9$.

35. Morais Silva P, Antunes J, Chambel M, Prates S, Leiria Pinto P. Diagnosis of eosinophilic esophagitis in an infant undergoing milk oral immunotherapy - a case report. Eur Ann Allergy Clin Immunol. 2014;46:154-6.
36. Rodriguez GC, Torrijos EG, De la Pinzón FR, Segade JB, Rodriguez RR, BritoFF, Rodriguez-D Sanchez J. Dysphagia in a boy treated with oral immunotherapy for cow's milk allergy. J Invest Allergol Clin Immunol; 2014, 24: 352-5.

37. Greifer M, Santiago MT, Tsirilakis K, Cheng JC, Smith LP. Pediatric patients with chronic cough and recurrent croup: the case for a multidisciplinary approach. Int J Pediatr Otorhinolaryngol.I 2015; 79:749-52.

38. Goldin AH, Chan WW. Current Approach to the Management of Eosinophilic Esophagitis in Adults. Curr Treat Options Gastroenterol. 2015; 13(4):441-51.

39. Aceves SS. Eosinophilic esophagitis. Immunol Allergy Clin North Am. 2015; 35(1):145-59.

40. Aceves SS. Food and aeroallergens in eosinophilic esophagitis: role of the allergist in patient management. Curr Opin Gastrenterol. 2014; 30:391-5.

41. González-Cervera J and Lucendo AJ. Eosinophilic esophagitis: An evidence based approach to therapy. J Investig Allergol Clin Immunol. 2016; 26(1): 8-18.

\section{Manuscript received July 3, 2016; accepted for publication, September 29, 2016.}

\section{Elisa Gómez Torrijos}

Hospital general de Ciudad Real

Servicio de Alergia

c/Obispo R Torija S/N

13005 Ciudad Real, Spain

E-mail: egomezt.cr@gmail.com 